\title{
Morular Metaplasia of the Endometrium
}

National Cancer Institute

\section{Source}

National Cancer Institute. Morular Metaplasia of the Endometrium. NCI Thesaurus. Code C37269.

A morphologic finding indicating the replacement of part of the glandular endometrial epithelium by nodular structures that contain non-keratinizing squamous cells. 